\title{
Proceeding
}

Supplementary Issue: Summer Conferences of Sports Science. Costa Blanca Sports Science Events, 25-26 September 2020. Alicante, Spain.

\section{Effects of power resistance training program with elastic bands on body composition, muscle strength and physical function in older women}

\author{
JORGE FLANDEZ ${ }^{1}$, JAVIER GENE-MORALES ${ }^{2,3}$, NICOLE MODENA ${ }^{3}$, FERNANDO MARTIN³ ${ }^{3}$, JUAN C. \\ COLADO $^{3} \triangle$, PEDRO GARGALLO $^{3}$ \\ ${ }^{1}$ Institute of Education Sciences, Austral University of Chile, Ciudad de Valdivia, Chile \\ ${ }^{2}$ Research Institute on Traffic and Road Safety (INTRAS), University of Valencia, Valencia, Spain \\ ${ }^{3}$ Research Unit in Sport and Health, University of Valencia, Valencia, Spain
}

\begin{abstract}
The aim of this study was to investigate the effects of a power-strength resistance program with elastic bands on body composition, physical function, and muscle strength in older women. For such purpose, a randomized controlled trial with a pre-post-intervention design was conducted. Thus, 58 healthy, physically independent, sedentary women, aged 65-85 years, were randomly allocated to the intervention $(n=28)$ or control group $(n=30)$. Measurements of body composition (total mass, total fat mass, total skeletal-muscle mass, and body fat percentage), isokinetic muscle strength of knee flexors and extensors (at $60 \%$ second and 180\%second), and physical performance (flexibility, agility/dynamic balance, and mobility) were taken pre-intervention and after 20 weeks of a power-strength protocol (light loads at maximum speed) with elastic bands consisting of 42 sessions (including familiarization) of between 80 and 90 minutes, with six exercises per session. The intensity was controlled with the OMNI-RES scale of perceived exertion. An analysis of variance (ANOVA) and covariance (ANCOVA) was carried out. All parameters of physical function, isokinetic strength, and body composition significantly improved $(p<.05)$ in the intervention group, except the muscle mass and the knee flexion strength at $60^{\circ} / \mathrm{sec}$, on which no statistical difference was observed $(p>.05)$. All the variables got worsened or did not change in the control group. A resistance program with elastic bands using light loads and performing at maximum speed can reverse the deterioration in body composition, muscle strength, and physical function, and offer significant physical benefits in sedentary older women.
\end{abstract}

Keywords: Resistance training; Variable resistance; Functional capacity; Elder people; Female.

Cite this article as:

Flandez, J., Gene-Morales, J., Modena, N., Martín, F., Colado, J.C., \& Gargallo, P. (2020). Effects of power resistance training program with elastic bands on body composition, muscle strength and physical function in older women. Journal of Human Sport and Exercise, 15(4proc), S1322-S1337. doi:https://doi.org/10.14198/jhse.2020.15.Proc4.30

Corresponding author. Department of Physical Education and Sports, University of Valencia. C/ Gascó Oliag 3, 46010, Valencia, Spain. https://orcid.org/0000-0002-3255-3940

E-mail: juan.colado@uv.es

Abstract submitted to: Spring Conferences of Sports Science. Costa Blanca Sports Science Events, 19-20 June 2020. Alicante, Spain.

JOURNAL OF HUMAN SPORT \& EXERCISE ISSN 1988-5202

(c) Faculty of Education. University of Alicante

doi:10.14198/jhse.2020.15.Proc4.30

S1322

| 2020 | Proc4 | VOLUME 15

(C) 2020 University of Alicante 


\section{INTRODUCTION}

The number of elderly individuals (those aged $>65$ years) is increasing worldwide (Saunder et al., 2015). This tendency is markedly observed in the European population, and specifically in Spain, which is expected to continue increasing in the next decades (Eurostat, 2020). As a result of increased life expectancy, biological changes associated with aging also increase, even in the absence of chronic disease.

Aging is associated with impairment of the neuromuscular system, including muscle atrophy (muscle mass decreases at a rate of $1 \%$ to $2 \%$ per year above the age of 50; von Haehling et al., 2010) and decreases in muscle strength (3\% after the age of 60; von Haehling et al., 2010). Furthermore, skeletal muscle power declines at a faster rate than muscle strength during aging (Leyva et al., 2016; Reid \& Balachandran, 2012), and it has been shown to be more important than muscle strength in the ability to perform daily activities (Bassey et al., 1992). As a consequence, even with healthy aging (in the absence of disease), aging is associated with an age-related physical function decline that is related with increased risk of falling (Moreira et al., 2018), disability (Evans et al., 2010) and loss of independence (Brady et al., 2014). In fact, it has been estimated that $23 \%$ of individuals aged between $60-69$ years show physical limitations that increase with age (Holmes et al., 2009), being women the most affected gender (Holmes et al., 2009). Given the neuromuscular consequences of aging, strategies for prevention and treatment are necessary to improve the health of older adults, and specifically to enhance their physical function and body composition.

Regular physical activity, and particularly, resistance training (exercise characterized by sets of repeated muscle contractions against an external load, interspersed by rest intervals) has been widely accepted as an effective intervention to attenuate the loss of muscle mass, to improve muscle strength and muscle power, and hence, to improve physical function in the elderly (Borde et al., 2015; Byrne et al., 2016; Chodzko-Zajko et al., 2009; Fragala et al., 2019; Gargallo et al., 2018). The American College of Sports Medicine (2009) position stand for healthy adults recommends performing resistance exercises, with a frequency of at least 2 days a week, and intensity between moderate and vigorous (5-6 and 7-8, respectively, on a scale from 0 to 10).

Numerous devices can be used for resistance training (i.e.: machines, free weights, elastic bands (EB), or chains). In particular, EB are becoming more popular for both health and physical performance (Colado et al., 2010; Colado \& Triplett, 2008; Gargallo et al., 2018). EB are accessible, inexpensive, easy to transport, handle, and maintain (Martins et al., 2013), and have been shown to induce similar neuromuscular activation and adaptations to free weights and machines (Colado et al., 2010; Colado \& Triplett, 2008). Two key points of training programs with elastic devices are that they can be performed at home (Chupel et al., 2017), and intensity can be controlled through the rate of perceived exertion (Colado \& Triplett, 2008; Colado et al., 2018).

Despite the recommendations of the ACSM, mainly in the last decade, it has been suggested that resistance training with the intention to move as fast as possible the load in the concentric phase, also known as "powerstrength training" or "high-velocity resistance training", might induce greater functional improvements by increasing in a greater extent the power output and the explosive force than slow to moderate velocity resistance training (Gray et al., 2018; Orssatto et al., 2019; Straight et al., 2015; Tschopp et al., 2011). Nevertheless, due to the heterogeneity of the training protocols, study samples, and the length of the interventions, is still no clear which kind of power -strength training can provide better results in terms of physical function and body composition in older adults, and more specifically in older women. Consequently, current data supporting resistance training with fast-intended concentric velocities in older persons are 
unclear, and the lack of knowledge is even more remarkable when variable resistance such as elastic bands is used instead of free weight or machines.

Therefore, this study aimed to investigate the effects of a power-strength resistance training program with elastic bands on body composition (total mass, total fat mass, total skeletal-muscle mass, and body fat percentage), muscle strength (isokinetic strength of knee flexors and extensors at $60 \%$ second and $180 \%$ second) and physical function (proactive balance, dynamic balance, muscle power strength, and aerobic endurance), in older women. We hypothesized that power-strength training will yield significant improvements in the neuro-muscular parameters evaluated.

\section{MATERIAL AND METHODS}

This was a 20-week randomized, double-blinded (participant and outcome assessor), prospective controlled trial with a pre-post intervention design. The subjects were randomized into power training $(P, n=34)$ or a self-management control $(C ; n=34)$ groups, by an independent staff member not involved in the study using a computer-generated random permutation procedure (Microsoft Excel). This study was approved by the Ethics Committee on Human Research of the University of Valencia (H1508742840440) so that all procedures described in this study met the established requirements of the declaration of Helsinki 1975, revised in 2008.

\section{Participants}

Healthy, Caucasian older women (aged > 60 years) were recruited from the Municipal Activity Centers for Older People (MACOP; Valencia, Spain) through non-probabilistic, convenience sampling (Thomas y Nelson, 2007), The inclusion criteria were: 1) age over 60 years; 2) physically independent (able to walk 100 meters without a walking aid and climb 10 steps without rest); 3) medical certificate of suitability or fitness to practice resistance training activities; 4) no plans to leave the area during the intervention; 5) cognitive ability to understand, follow the instructions and sign the informed consent form; 6) free of medications that were expected to alter the results of the study (ergogenic or dietary aids, estrogen, steroid hormones, calcitonin, or corticosteroids) for at least 6 weeks before the start of the study; 7 ) willingness to be randomized to either intervention group and to follow the study protocol. In turn, the exclusion criteria were: 1) presence of cardiovascular, musculoskeletal, renal, liver, or neuromuscular disorders that would prevent the participant from performing the exercises; 2) body weight changes $>10 \%$ in the previous year; 3 ) history of malignant neoplasms; 4) engagement in regular strength training (more than once a week) during the previous 6 months; 5) individuals participating in another research project (within the last 6 months) involving dietary, exercise and/or pharmaceutical intervention; 6) Mini-Mental State Examination lower than 23/30; and 7) severe visual or hearing impairment.

An informative meeting was carried out with all persons interested in participating in the study. All potential participants selected after the informative meeting received written and verbal information about the purpose and procedures of the study as well as the benefits, risks, and discomfort that might result from participation. Each participant provided informed consent before the start of the study and was free to withdraw from the study at any time.

Participants of both groups ( $P$ and $C$ ) were requested to maintain their eating habits and habitual physical activity and to not participate in other alternative exercise programs during the research period. 


\section{Measures}

Baseline and post-intervention evaluations were carried out two weeks prior and after the intervention and consisted of the assessment of the following primary and secondary variables: anthropometry (height and weight), body composition (total body mass, total fat mass, total fat-free mass, and total percentage of fat mass), muscle strength of lower limbs (isokinetic strength of knee flexion and extension muscles at $60 \%$ and $180 \%$ s) and physical function [proactive balance by the functional reach test (FRT); dynamic balance by time up \& go test (TUG); muscle power of lower limbs by the time stair climbing test (SCT); and the aerobic endurance though the 6-minute walking test (6MWT). The order of the tests was firstly body composition, followed by isokinetic strength, and finally physical function (TUG followed by FRT, SCT, and 6MWT).

Both initial and final assessments were performed by the same trained researchers. All the tests were carried out at the performance laboratory of the University of Valencia (Valencia, Spain).

\section{Anthropometric and body composition measurements}

Before each test, height and weight were recorded to the nearest $0.01 \mathrm{~cm}$ and $0.01 \mathrm{Kg}$, respectively, using a stadiometer (Seca 711, Hamburg, Germany) and a Tanita® BC-418MA digital scale (Tanita Corp., Tokyo, Japan).

Body composition was evaluated by a whole-body scan using a Dual-energy X-ray Absorptiometry (DXA) (fan beam technology QDR® Hologic Discovery Wi, Hologic Inc., Waltham, MA, USA) equipped with APEX software (APEX Corp., version 12.4, Waltham, MA, USA). Quality control calibration procedures were performed using a spine phantom (Hologic X-CALIBER Model DPA/QDR-1; Hologic, Inc., Waltham, MA, USA) before each testing session according to the manufacturer's instructions.

The participants were positioned in the supine position of the DXA table, with their arms placed close to the sides, hands lying flat and pronated and the legs secured in place using Velcro straps, maintaining hips at 25 degrees of internal rotation, according to the instructions of manufacturer instructions, required to remain motionless throughout the examination. Participants were asked to wear shorts and a t-shirt and to remove any metal or plastic materials they were wearing. They were scanned at the same time of the day (in the morning) in a fasted state, by the same certified investigator, and on the same machine. DXA is a highly reliable and accurate method of determining soft-tissue body composition (Lohman et al., 2009). For longitudinal studies in which relatively small changes in body composition need to be detected, whole-body scanning with this instrument has demonstrated to be accurate and reliable (coefficient of variation $0.8-2.8 \%$ ) (Prior et al., 1997).

\section{Isokinetic strength}

All tests were performed using the Biodex® Multi-joint System V.4X (Biodex Medical TM, Shirley, NY, USA) isokinetic dynamometer, calibrated before each test according to the instructions of the manufacturer (Lord et al., 1992). The dynamic and continuous concentric-concentric contraction cycle of knee flexion-extension was performed at angular velocities of $60 \% \mathrm{sec}$ and $180^{\circ} / \mathrm{sec}$. These are considered to be the optimum velocity for the measurement of maximum and power strength, respectively (Dvir, 2004). Each test consisted of one set of five maximum voluntary contractions on the dominant side, with a recovery period of two minutes between tests. In each test, the angular velocity of $180 \%$ s was always firstly analysed followed by the $60 \%$, with a rest period between them of 60 seconds. During the concentric tests, the subjects continuously pushed the lever arm of the isokinetic device up and down through the whole range of motion (ROM), between 0 to $5^{\circ}$ and 85 to $90^{\circ}$ of knee flexion ( $85^{\circ}$ of ROM). 
Gravity correction was applied. The test procedures complied with reproducibility criteria (axes of movement, subject position, the position of proximal joints and attachments, and stabilizing straps), adjusting the positions of the dynamometer and the seat for each movement according to the anthropometry of each subject.

As subjects did not have previous experience with the isokinetic dynamometer, they were familiarized with a trial phase of 30 seconds continuous concentric-concentric cycles (3-5 submaximal contractions) at the test velocity that was to be recorded to become accustomed to the movement, a 1-minute rest, and an actual test phase of five continuous concentric-concentric cycles (Kramer, 1990). During the 30 seconds of familiarization, at least one trial had to be a maximal contraction, as recommended by Snow and Blacklin (1992). Peak torque (Nm) was recorded for each trial, and only the best result of the five cycles was used for subsequent analysis.

\section{Functional reach test}

This test was aimed to assess proactive balance (Duncan et al., 1990). Each subject stood adjacent to a wall on which a meter stick was fixed at the level of the acromion and parallel to the ground. They were instructed to lift the arm closest to the wall to horizontal (arm parallel to the ground, elbows extended, neutral pronationsupination forearm, closed fists) and reach as far as possible without stepping, touching the wall, or rotating the body (feet static on the ground and body displacement on the sagittal plane). The evaluator recorded the position of the middle-finger metacarpal in the starting and final positions. The functional range was calculated in centimetres $(\mathrm{cm})$ as the difference between the final position of the third goal minus the initial position of the same. Each subject completed three attempts, with the average of the two largest used for subsequent analysis. Minimum rest was given between attempts.

\section{Up\&Go test}

This test was aimed to assess dynamic balance and agility (Rikli \& Jones, 2013). The subject was seated on the middle of a chair (in contact with a wall behind it), back straight (slightly inclined forward), feet on the floor (one foot slightly forward compared to the other), and hands on thighs. On the charge signal "ready, go", they had to stand up and walk a straight line as quickly as possible (no running or jogging allowed) to a cone placed at 8 feet (2.44 meters, measured from the back of the cone to the front edge of the chair), turn around the cone, and sit down again. Prior to the test, the participants performed one trial. The time started counting with the "go" signal and was stopped when the participant sat in the chair. Results were recorded in seconds (s). The test was carried out twice, with minimum rest between attempts, and the best score was recorded for statistical analyses.

\section{Time Stair Climbing test}

The muscle power of lower limbs was assessed by the Stair Climbing Test (SCT) (Bennell et al., 2011). Participants ascended, after the tester gave the start sign "Ready, Set, Go", two flights of stairs (eleven stairs per flight, with an 18-cm rise per stair) as quickly as possible without using the handrails or any other aid but safely (handrail and tester were available for balance support only if needed) The time to complete this task was recorded. Two attempts with a 3-minutes pause between them were performed. The best time of both attempts was recorded for statistical analyses.

\section{6-minute walk test}

This test was aimed to evaluate aerobic endurance (Rikli \& Jones, 2013). It was carried out in an open space, with a flat and hard surface, located in the Faculty of Physical Activity and Sports Science and Physiotherapy of Valencia. A round circuit of 30 -meters long (60 meters each lap) and 4-meters wide was prepared before 
the start of the test. The two turning points were signalled by cones. Marks were made every 3 meters with tape to ease an accurate measurement of the total distance covered by the subjects (in meters [m]). A researcher explained the procedures before starting. On the charge signal "ready, go", subjects had to walk the delimited route as fast as possible (no running or jogging allowed) for 6 minutes. A verbal notification was used to indicate minutes 3 and 4 to help subjects regulate their rhythm. Once the 6 minutes elapsed, the participants had to stop and stand still for the researcher to record the distance covered in the last lap (to add it to the total laps); one of the cones or the marks done each 3 meters were used as a reference. Before starting the test, participants were instructed that if at any time during the test they manifested symptoms of abnormal exhaustion, they could slow down or simply stop. Each subject was verbally stimulated throughout the test. Only one attempt was performed.

\section{Exercise intervention}

The 20-week training program (from February to July) was composed of 38 sessions (42 including the four familiarization sessions) of approximately 80 minutes, performed twice a week on non-consecutive days (Tuesday and Friday). Each training session started with a general warm-up of 5-10 minutes composed of joint mobility exercises, coordinating exercises, and active mobility. Subsequently, the main part was composed of 6 strength exercises (see "Exercises" section) with a duration of 60 minutes. Finally, a cooldown period with a duration of approximately 10 minutes and composed of active, static stretching exercises was carried. The assistance was controlled by collaborating staff. All of the sessions were carried out in the multipurpose rooms of the respective MACOP being all of them equipped with air handlers to maintain similar environmental conditions $\left(21-22^{\circ} \mathrm{C}\right)$. The sessions were always directed by the same instructors. Also, a supervisor was present to monitor the methodology, performance, materials, room conditioning, and adherence to the program.

The participants underwent 4 sessions of familiarization in two weeks before the start of the training program. These sessions were aimed at instructing the subjects on how to perform the exercises (i.e. initial and final positions, control of breathing, avoiding Valsalva manoeuvre, use of elastic bands, speed of execution), and how to use the scales of perceived effort (Colado et al., 2018) and velocity (Bautista et al., 2014a). The intensity was monitored through the number of repetitions and the rate of perceived effort with the OMNIRES EB scale validated for older people (see Colado et al., 2018). This 0-10 scale was applied following the methods described in previous researches (Colado et al., 2010; Colado \& Triplett, 2008). The speed was monitored with a scale of perception of velocity (see Bautista et al., 2014a). Also, a metronome set up at 120 beats per minute (bpm) and music at the same bpm were used to mark the appropriate cadence to perform the exercises (i.e. concentric phase at maximum speed, 1-beat stop at the transition, and 2-3 beats eccentric phase).

\section{Exercises}

Both polyarticular and monoarticular exercises involving the main muscle groups of the upper and lower limbs alternately were included in the intervention, according to the recommendations of the ACSM («American College of Sports Medicine», 2009). The exercises included two specific exercises for the upper limb (biceps curl and horizontal chest press), two specific exercises for the lower limb (lunge and standing hip abduction), and two exercises involving muscle groups of the upper and lower limb (squat + upright rowing and squat + military shoulder press). The exercises were always performed in the following order: squat + upright rowing, biceps curl, lunges, chest press, squat + military shoulder press, standing hip abduction. The exercises were performed with CLX looped elastic bands (TheraBand (B; Hygenic Corporation, Akron, OH, USA). 


\section{Training load}

Subjects performed 10 repetitions (the first two weeks 12 repetitions were made to consolidate the technique) of each exercise at maximum concentric speed (perception of "fast" in the velocity scale) with loads between 40 and $60 \%$ of one-repetition maximum (RM); values between 3-4 (first repetition) and 6 (last repetition) in the OMNI-RES scale. Thus, a high-velocity displacement of the load was guaranteed, essential to achieve functional improvements (Bautista et al., 2014b). The volume during the first 2 months (8 weeks) was 3 sets per exercise and increased to 4 for the remaining 12 weeks, with 90 seconds of active recovery between sets. Active recovery, which consisted of programmed choreographies of coordinative movements, was a strategy to improve adherence and in addition to increase caloric expenditure and improve the cardiovascular system. Non-active pauses of 60 seconds were also allowed between exercises (macro pauses) to hydrate and/or dry up the sweat.

\section{Data analysis}

The assumption of normality and homogeneity of the dependent variables was verified with the KolmogorovSmirnov and Levene tests, respectively. Descriptive variables from both groups were compared using an unpaired t-test. An analysis of variance (ANOVA) for repeated measures followed by Bonferroni corrections was used to analyse within- and between-group comparisons on dependent variables (body composition, muscle strength, and physical function), having experimental groups ( $\mathrm{P}$ and $\mathrm{C}$ ) and time (baseline and followup) as factors. In addition, analysis of covariance (ANCOVA) for repeated measures was also used to correct for initial group differences at the conclusion of the study using baseline values as covariate and adjusting also for age. All the cases complied with Mauchly's sphericity assumption. Cohen's d effect sizes (ES) were calculated according to the methodological procedures defined by Cohen (2013) and interpreted as 'trivial' $(<0.2)$ 'small' (>0.2-0.49), 'moderate' (>0.5-0.79.2), and 'large' (>0.80). The delta percentage $(\Delta \%)$ was calculated with the standard formula: change $(\%)=[($ posttest score - pretest score $) /$ pretest score $] \times 100 . A$ $95 \%$ confidence level (significance $p<.05$ ) was accepted as statistically significant. Statistical analysis was carried out using commercial software IBM SPSS Statistics for Macintosh (Version 25.0; IBM Corp., Armonk, NY). All data are reported as the means \pm the standard deviations and the $95 \%$ confidence interval.

\section{RESULTS}

68 healthy older women started the intervention and 58 of them finished it ( $P ; n=28$; age: $67.81 \pm 5.21$ years; weight: $68.00 \pm 10.46 \mathrm{~kg}$; height: $1.52 \pm 0.06 \mathrm{~m})(\mathrm{C} ; \mathrm{n}=30$; age: $67.75 \pm 4.91$ years; weight: $70.73 \pm 9.63 \mathrm{~kg}$; height: $1.58 \pm 0.06 \mathrm{~m})$. Significant differences $(p>.05)$ were only found between the height of both groups. The attendance rate for the $\mathrm{P}$ group was above $85 \%$ [ $87.80 \%$ (36 of 41 sessions) including the familiarization sessions]. During the intervention period, 6 and 4 women for $P$ and $C$ groups respectively dropped out of the study. However, none of them were due to adverse events derived from training or testing processes. Results of the intervention in body composition, isokinetic strength, and physical function tests in both groups are presented in Table 1, Table 2, and Table 3, respectively.

\section{DISCUSSION}

The present study showed that a 20 -week power-resistance training program with elastic bands is an effective strategy to improve body composition, muscle strength, and physical function in older women, confirming the hypothesis previously reported. This section will be developed divided into three sections (body composition, isokinetic strength, and physical function). 
Table 1. Intervention effects on body composition. Data are expressed as mean \pm standard deviation and confidence interval (95\% Cls). Sample size of each group: $\mathrm{P}(n=28), \mathrm{C}(n=30)$.

\begin{tabular}{|c|c|c|c|c|c|c|c|c|}
\hline Variables & Group & Baseline & Post-test & $\Delta \%$ & $\begin{array}{c}\mathrm{p} \text {-value (ES) } \\
\text { ANOVA (time) }\end{array}$ & $\begin{array}{l}\text { p-value (ES) } \\
\text { ANCOVA } \\
\text { (time) }\end{array}$ & $\begin{array}{l}\text { p-value (ES) } \\
\text { ANOVA } \\
\text { (group x time) }\end{array}$ & $\begin{array}{l}\text { p-value (ES) } \\
\text { ANCOVA } \\
\text { (group x time) }\end{array}$ \\
\hline $\begin{array}{l}\text { Total body } \\
\text { mass }\end{array}$ & $P$ & $\begin{array}{l}66.12 \pm 9.96 \\
(62.08-70.16)\end{array}$ & $\begin{array}{l}65.65 \pm 10.02 \\
(61.62-69.69)\end{array}$ & -0.71 & $.027(0.05)$ & $.022(0.05)$ & \multirow{2}{*}{ P vs C: $.400(0.55)$} & \multirow{2}{*}{ P vs C: .032(0.09) } \\
\hline$(\mathrm{Kg})$ & C & $\begin{array}{l}70.56 \pm 9.15 \\
(66.66-74.47)\end{array}$ & $\begin{array}{l}70.90 \pm 9.04 \\
(67.00-74.80)\end{array}$ & 0.48 & $.097(0.04)$ & $.089(0.04)$ & & \\
\hline $\begin{array}{l}\text { Total fat } \\
\text { mass }\end{array}$ & $P$ & $\begin{array}{l}28.38 \pm 6.37 \\
(25.63-31.12)\end{array}$ & $\begin{array}{l}27.43 \pm 6.43 \\
(24.71-30.14)\end{array}$ & -3.35 & $.000(0.15)$ & $.000(6.39)$ & \multirow{2}{*}{ P vs C: .196 (0.18) } & \multirow{2}{*}{ P vs C: $.000(0.01)$} \\
\hline $\begin{array}{l}\text { mass } \\
(\mathrm{Kg})\end{array}$ & C & $\begin{array}{l}30.83 \pm 6.22 \\
(28.18-33.48)\end{array}$ & $\begin{array}{l}31.55 \pm 6.14 \\
(28.92-34.17)\end{array}$ & 2.31 & $.002(0.12)$ & $.000(7.08)$ & & \\
\hline $\begin{array}{l}\text { Total fat } \\
\text { free mass }\end{array}$ & $P$ & $\begin{array}{l}35.96 \pm 3.96 \\
(34.37-37.55)\end{array}$ & $\begin{array}{l}36.25 \pm 4.10 \\
(34.61-37.89)\end{array}$ & 0.80 & $.122(0.07)$ & $.118(0.07)$ & \multirow{2}{*}{ P vs C: $1.000(0.29)$} & \multirow{2}{*}{ P vs C: $.006(0.21)$} \\
\hline $\begin{array}{l}\text { Tree mass } \\
(\mathrm{Kg})\end{array}$ & C & $\begin{array}{l}37.95 \pm 3.97 \\
(36.41-39.48)\end{array}$ & $\begin{array}{l}37.39 \pm 3.85 \\
(35.80-38.97)\end{array}$ & -1.47 & $.002(0.14)$ & $.001(0.15)$ & & \\
\hline Total fat & $P$ & $\begin{array}{l}42.46 \pm 4.15 \\
(40.72-44.20)\end{array}$ & $\begin{array}{l}40.55 \pm 4.42 \\
(38.80-42.31)\end{array}$ & -4.49 & $.000(0.44)$ & $.000(0.45)$ & \multirow{2}{*}{ P vs C: .018 (0.3) } & \multirow{2}{*}{ P vs C: $.000(0.12)$} \\
\hline & C & $\begin{array}{l}43.36 \pm 4.27 \\
(41.68-45.04)\end{array}$ & $\begin{array}{l}44.28 \pm 4.12 \\
(42.59-45.98)\end{array}$ & 2.13 & $.000(0.22)$ & $.000(0.22)$ & & \\
\hline
\end{tabular}

P: power training group; C: control group; Cls: Coefficient intervals; ES: effect size; ANOVA: analysis of variance; ANCOVA: analysis of covariance; $\triangle \%$ : percentage of change. Covariates appearing in the model are evaluated by baseline values of dependent variables and age. 
Table 2. Intervention effects on isokinetic strength of knee flexors and extensors muscles. Data are expressed as mean \pm standard deviation and confidence interval (95\% Cls). Sample size of each group: $P(n=28), C(n=30)$.

\begin{tabular}{|c|c|c|c|c|c|c|c|c|}
\hline Variables & Group & Baseline & Post-test & $\Delta \%$ & $\begin{array}{c}\text { p-value (ES) } \\
\text { ANOVA (time) }\end{array}$ & $\begin{array}{l}\text { p-value (ES) } \\
\text { ANCOVA } \\
\text { (time) }\end{array}$ & $\begin{array}{l}\text { p-value (ES) } \\
\text { ANOVA } \\
\text { (group x time) }\end{array}$ & $\begin{array}{l}\text { p-value (ES) } \\
\text { ANCOVA } \\
\text { (group x time) }\end{array}$ \\
\hline $\begin{array}{l}\text { Knee flex. } \\
180^{\circ} / \mathrm{s}\end{array}$ & $P$ & $\begin{array}{l}26.01 \pm 8.19 \\
(23.15-28.87)\end{array}$ & $\begin{array}{l}32.66 \pm 8.05 \\
(29.66-35.65)\end{array}$ & 25.55 & $.000(0.82)$ & $.000(0.79)$ & \multirow[t]{2}{*}{ P vs C: .000 (1.04) } & \multirow[t]{2}{*}{ P vs C: $.000(0.89)$} \\
\hline$(\mathrm{N} \cdot \mathrm{m})$ & C & $\begin{array}{l}24.36 \pm 8.76 \\
(21.60-27.12)\end{array}$ & $\begin{array}{l}23.88 \pm 8.71 \\
(20.99-26.77)\end{array}$ & -1.96 & $.646(0.05)$ & $.268(0.13)$ & & \\
\hline $\begin{array}{l}\text { Knee ext. } \\
180^{\circ} / \mathrm{s}\end{array}$ & $P$ & $\begin{array}{l}49.11 \pm 12.36 \\
(43.95-54.26)\end{array}$ & $\begin{array}{l}60.35 \pm 10.03 \\
(55.49-65.21)\end{array}$ & 22.89 & $.000(1)$ & $.000(0.96)$ & \multirow{2}{*}{ P vs C: .018 (0.33) } & \multirow{2}{*}{ P vs C: $.000(0.52)$} \\
\hline$(\mathrm{N} \cdot \mathrm{m})$ & $C$ & $\begin{array}{l}49.33 \pm 16.66 \\
(44.35-54.30)\end{array}$ & $\begin{array}{l}50.02 \pm 16.18 \\
(45.32-54.71)\end{array}$ & 1.41 & $.675(0.04)$ & $.854(0.02)$ & & \\
\hline $\begin{array}{l}\text { Knee flex. } \\
60^{\circ} / \mathrm{s}\end{array}$ & $P$ & $\begin{array}{l}41.38 \pm 10.51 \\
(37.57-45.20)\end{array}$ & $\begin{array}{l}42.91 \pm 10.64 \\
(39.23-46.58)\end{array}$ & 3.68 & $.153(0.14)$ & $.126(0.14)$ & \multirow{2}{*}{ P vs C: .175 (0.55) } & \multirow{2}{*}{ P vs C: .144 (0.3) } \\
\hline$(\mathrm{N} \cdot \mathrm{m})$ & $C$ & $\begin{array}{l}38.15 \pm 10.92 \\
(34.46-41.84)\end{array}$ & $\begin{array}{l}37.21 \pm 10.21 \\
(33.66-40.76)\end{array}$ & -2.46 & $.359(0.09)$ & $.093(0.15)$ & & \\
\hline $\begin{array}{l}\text { Knee ext. } \\
60^{\circ} / \mathrm{s}\end{array}$ & $P$ & $\begin{array}{l}84.89 \pm 16.95 \\
(77.06-92.72)\end{array}$ & $\begin{array}{l}91.60 \pm 19.26 \\
(83.60-99.61)\end{array}$ & 7.91 & $.001(0.37)$ & $.001(0.36)$ & \multirow{2}{*}{ P vs C: .864 (0.53) } & \multirow{2}{*}{ P vs C: $.031(0.22)$} \\
\hline$(\mathrm{N} \cdot \mathrm{m})$ & C & $\begin{array}{l}84.01 \pm 25.34 \\
(76.44-91.57)\end{array}$ & $\begin{array}{l}83.34 \pm 24.44 \\
(75.61-91.07)\end{array}$ & -0.79 & $.719(0.03)$ & $.569(0.04)$ & & \\
\hline
\end{tabular}

P: power training group; C: control group; Cls: Coefficient intervals; ES: effect size; ANOVA: analysis of variance; ANCOVA: analysis of covariance; $\triangle \%$ : percentage of change; ext.: extension; flex: flexion. Covariates appearing in the model are evaluated by baseline values of dependent variables and age. 
Table 3. Intervention effects on physical function. Data are expressed as mean \pm standard deviation and confidence interval ( $95 \%$ Cls). Sample size of each group: $P(n=28), C(n=30)$.

\begin{tabular}{|c|c|c|c|c|c|c|c|c|}
\hline Variables & Group & Baseline & Post-test & $\Delta \%$ & $\begin{array}{l}\text { p-value (ES) } \\
\text { ANOVA (time) }\end{array}$ & $\begin{array}{l}\text { p-value (ES) } \\
\text { ANCOVA (time) }\end{array}$ & $\begin{array}{l}\text { p-value (ES) } \\
\text { ANOVA } \\
\text { (group x time) }\end{array}$ & $\begin{array}{l}\text { p-value (ES) } \\
\text { ANCOVA } \\
\text { (group x time) }\end{array}$ \\
\hline \multirow{2}{*}{$\begin{array}{l}\text { FRT } \\
(\mathrm{cm})\end{array}$} & $P$ & $\begin{array}{l}23.31 \pm 6.01 \\
(21.14-25.48)\end{array}$ & $\begin{array}{l}27.21 \pm 4.69 \\
(25.19-29.24)\end{array}$ & 16.75 & $.000(0.72)$ & $.000(0.58)$ & \multirow{2}{*}{ P vs C: $1.000(0.05)$} & \multirow[b]{2}{*}{ P vs C: .032 (0.54) } \\
\hline & C & $\begin{array}{l}26.74 \pm 5.92 \\
(24.64-28.84)\end{array}$ & $\begin{array}{l}26.25 \pm 6.20 \\
(24.30-28.21)\end{array}$ & -1.83 & $.553(0.08)$ & $.882(0.02)$ & & \\
\hline \multirow{2}{*}{$\begin{array}{l}\text { TUG } \\
\text { (s) }\end{array}$} & $P$ & $\begin{array}{l}6.10 \pm 0.95 \\
(5.75-6.44)\end{array}$ & $\begin{array}{l}5.23 \pm 0.67 \\
(4.92-5.54)\end{array}$ & -14.21 & $.000(1.04)$ & $.000(0.97)$ & \multirow[b]{2}{*}{ P vs C: .014 (0.68) } & \multirow[b]{2}{*}{ P vs C: $.000(0.05)$} \\
\hline & C & $\begin{array}{l}5.80 \pm 0.99 \\
(5.47-6.13)\end{array}$ & $\begin{array}{l}5.91 \pm 1.23 \\
(5.61-6.21)\end{array}$ & 1.88 & $.432(0.1)$ & $.813(0.02)$ & & \\
\hline \multirow{2}{*}{$\begin{array}{l}\text { SCT } \\
\text { (s) }\end{array}$} & $P$ & $\begin{array}{l}13.04 \pm 1.84 \\
(12.05-14.02)\end{array}$ & $\begin{array}{l}11.52 \pm 1.42 \\
(10.63-12.41)\end{array}$ & -11.66 & $.000(0.92)$ & $.000(0.98)$ & \multirow{2}{*}{ P vs C: .006 (0.01) } & \multirow{2}{*}{ P vs C: $.000(0.82)$} \\
\hline & C & $\begin{array}{l}13.31 \pm 2.85 \\
(12.36-14.26)\end{array}$ & $\begin{array}{l}13.65 \pm 2.96 \\
(12.79-14.51)\end{array}$ & 2.52 & $.137(0.12)$ & $.137(0.11)$ & & \\
\hline \multirow{2}{*}{$\begin{array}{l}\text { 6MWT } \\
(\mathrm{m})\end{array}$} & $P$ & $\begin{array}{l}537.42 \pm 70.29 \\
(514.90-559.95)\end{array}$ & $\begin{array}{l}563.42 \pm 59.60 \\
(541.31-585.54)\end{array}$ & 4.84 & $.001(0.4)$ & $.000(0.41)$ & \multirow{2}{*}{ P vs C: .024 (0.78) } & \multirow{2}{*}{ P vs C: .001 (0.14) } \\
\hline & C & $\begin{array}{l}525.86 \pm 63.10 \\
(504.10-547.62) \\
\end{array}$ & $\begin{array}{l}517.76 \pm 58.18 \\
(496.39-539.13)\end{array}$ & -1.54 & $.274(0.13)$ & $.100(0.19)$ & & \\
\hline
\end{tabular}

P: power training group; C: control group; Cls: Coefficient intervals; ES: effect size; ANOVA: analysis of variance; ANCOVA: analysis of covariance; $\triangle \%$ : percentage of change; rep: repetitions; FRT: functional reach test; TUG: timed up and go test; SCT: time stair climbing test; 6MWT: six minutes walking test. Covariates appearing in the model are evaluated by baseline values of dependent variables and age. 


\section{Body composition (see Table 1 for further information)}

Significant improvements in body composition were observed in the intervention group, with a significant decrease in the whole-body fat mass and $\%$ of fat mass $(p<.005)$ and an increase in muscle mass although the increment was not significant by time $(p>.05)$. However, significant differences between groups at this parameter were observed at the end of the intervention. In addition, significant deterioration of body composition parameters in the control group was found, which is indicative of how fast the deleterious changes by age in this population are (Clark \& Manini, 2012). The magnitude of the change in base of the ES was between "trivial" (muscle mass) and "large" (fat mass).

Our findings are in accordance with previous studies that demonstrated improvements in different parameters of body composition in terms of fat mass with different power-strength exercise programs, using both elastic and constant resistance (De Resende-Neto et al., 2019; Fritz et al., 2018; Huang et al., 2017; Liao et al., 2018; Radaelli et al., 2018; Reid et al., 2015). In contrast, one study did not find changes in body composition after 12 weeks of varied training methods (Leite et al., 2015). Regarding muscle mass, some evidence suggests that power resistance training results in greater benefits than traditional resistance training for increasing lean mass, but results remain inconsistent (Coelho-Junior et al., 2019; De Resende-Neto et al., 2019; Gray et al., 2018; Henwood et al., 2008; Reid et al., 2008). Understanding that loss of muscle mass and obesity can improve the probability of suffering metabolic diseases, cardiovascular morbidity, and mortality (Wannamethee \& Atkins, 2015), our results highlight the usefulness of this method of training with elastic bands to control these parameters, and thus potentially improving life expectancy.

\section{Isokinetic strength (see Table 2 for further information)}

Significant improvements in isokinetic strength were found in all the parameters for the $\mathrm{P}$ group, with the exception of the strength of knee muscle flexors at $60 \%$. The time-course analysis revealed no significant changes in the $\mathrm{C}$ group in any parameter.

Power-strength training with elastic bands has proven useful to increase knee flexion-extension peak torque at $180 \%$, and knee flexion peak torque at $60 \%$ s. As expected, the increase of maximal strength at higher velocities $(180 \% \mathrm{~s})$ also called power strength, was higher at both flexors and extensors muscles, than at lower velocities. In fact, ES at higher velocities were "large" while at lower velocities were "small". The increases achieved are in accordance with those reported by Da Rosa Orsato and colleagues (2019) in their review which indicated that weekly improvements of dynamic strength of $2.16 \pm 0.94 \%$ can be achieved by power-resistance training in older adults. There were differences between groups in all the tests except for the knee flexion at lower velocities.

Numerous studies using constant and elastic resistances in interventions of between 8 and 24 weeks in different population groups, including older women, confirmed that power-strength training improves maximal strength parameters (Coelho-junior et al., 2019; De Resende-Neto et al., 2019; Fritz et al., 2018; Holmes et al., 2009). Bearing in mind our results and all the aforementioned researches, we can state that a resistance training program focused on power-strength using elastic bands is an effective strategy to increase the strength in the elderly. In this regard, muscle strength is considered one important predictor of mobility limitation and other associated problems in the elderly, like increased risk of fall and hospitalization (Manini et al., 2007). Previous researches revealed significant associations between performing resistance exercises, muscle strength, and functional parameters related to daily activities in old individuals (Gray et al., 2018). 


\section{Physical function (see Table 3 for further information)}

After 20 weeks of intervention, the P group showed significant improvements $(p<.001)$ in all the physical function tests, with "large" ES in three of them (FRT, TUG, and SCT) and "small" effects on the aerobic endurance test. No significant differences by the time were found in the $C$ group. Moreover, significant differences between groups were also found in all the physical function tests.

Our findings are supported by a previous wide range of literature which found improvements in the physical function with power-strength training interventions both with elastic bands and constant resistance in physical function parameters (Coelho-junior et al., 2019; Da Rosa Orsato et al., 2019. De Resende-Neto et al., 2019; Gray et al., 2018; Leite et al. 2015; Liao et al., 2018). More specifically, Holmes et al. (2009) found an enhancement in the 6MWT performance after a functional training program. Also, Bottaro et al. (2007) and Gray et al. (2018) found improvements in the TUG test performance. According to our results, Oesen and colleagues (2015) exposed that resistance training with elastic bands can achieve more pronounced effects on functional performance than on muscle strength (Oesen et al., 2015).

It seems that the simultaneous improvements of power strength by increasing the power output at high velocities and body composition by decreasing body fat and increasing muscle mass have been beneficial for functional improvements, without distinction of the functional capacity analysed (proactive and active balance, muscle power or aerobic endurance).

\section{Limitations and future directions}

Even though all the procedures and statistical analyses were carefully carried out, there are some limitations in the design of this study that should be listed. Firstly, only relatively healthy older women were analysed which is not possible to extend our findings to the male gender or older adults with health-specific conditions. Second, it could be possible that applying higher training frequencies the benefits could be better. This issue should be investigated in future studies. Finally, further research on different resistance training methods with elastic bands and their effects on other physical and physiological variables is expected to enrich the scientific knowledge.

\section{CONCLUSION}

A 20-week power-resistance training using elastic bands appears to be a safe and effective, alternative method to improve body composition, muscle strength, and physical function in older women. These results suggest that the enhancement of the parameters analysed in this study by the power-resistance training is necessary to prevent and treat the biological adverse events of aging, trying to increase the quality of life of the elderly people. Elastic bands are, once again, presented as an accessible, economic, simple-toimplement device to perform resistance exercises in the elderly.

\section{REFERENCES}

American College of Sports Medicine, Chodzko-Zajko, W. J., Proctor, D. N., Fiatarone Singh, M. A., Minson, C. T., Nigg, C. R., Salem, G. J. and Skinner, J. S. (2009). American College of Sports Medicine position stand. Exercise and physical activity for older adults. Medicine and Science in Sports and Exercise, 41(7), 1510-1530. https://doi.org/10.1249/MSS.0b013e3181a0c95c

Bautista, I. J., Chirosa, I. J., Chirosa, L. J., Martín, I., González, A. and Robertson, R. J. (2014a). Development and validity of a scale of perception of velocity in resistance exercise. Journal of Sports Science \& Medicine, 13(3), 542-549. 
Bautista, I. J., Chirosa, I. J., Tamayo, I. M., González, A., Robinson, J. E., Chirosa, L. J. and Robertson, R. J. (2014b). Predicting power output of upper body using the OMNI-RES Scale. Journal of Human Kinetics, 44, 161-169. https://doi.org/10.2478/hukin-2014-0122

Bassey, E. J., Fiatarone, M. A., O'Neill, E. F., et al. (1992). Leg extensor power and functional performance in very old men and women. Clinical Science,82, 321-327. https://doi.org/10.1042/cs0820321

Bennell, K., Dobson, F. and Hinman, R. (2011). Measures of physical performance assessments: SelfPaced Walk Test (SPWT), Stair Climb Test (SCT), Six-Minute Walk Test (6MWT), Chair Stand Test (CST), Timed Up \& Go (TUG), Sock Test, Lift and Carry Test (LCT), and Car Task. Arthritis Care \& Research, 63(S11), S350-S370. https://doi.org/10.1002/acr.20538

Borde, R., Hortobágyi, T. and Granacher, U. (2015). Dose-response relationships of resistance training in healthy old adults: a systematic review and meta-analysis. Sports Medicine, 45(12), 1693-1720. https://doi.org/10.1007/s40279-015-0385-9

Bottaro, M., Machado, S. N., Nogueira, W., Scales, R. and Veloso, J. (2007). Effect of high versus lowvelocity resistance training on muscular fitness and functional performance in older men. European Journal of Applied Physiology, 99(3), 257-264. https://doi.org/10.1007/s00421-006-0343-1

Brady, A. O., Straight, C. R. and Evans, E. M. (2014). Body composition, muscle capacity, and physical function in older adults: an integrated conceptual model. Journal of Aging and Physical Activity, 22(3), 441-452. https://doi.org/10.1123/JAPA.2013-0009

Byrne, C., Faure, C., Keene, D. J. and Lamb, S. E. (2016). Ageing, muscle power and physical function: a systematic review and implications for pragmatic training interventions. Sports Medicine, 1-22. https://doi.org/10.1007/s40279-016-0489-x

Chodzko-Zajko, W. J., Proctor D. N., Fiatarone Singh, M. A., Minson, C. T., Nigg, C. R., Salem, G. J. and Skinner J. S. (2009). Exercise and physical activity for older adults. Medicine and Science in Sports and Exercise, 41, 1510-1530. https://doi.org/10.1249/MSS.0b013e3181a0c95c

Chupel, M. U., Direito, F., Furtado, G. E., Minuzzi, L. G., Pedrosa, F. M., Colado, J. C., ... Teixeira, A. $M$. (2017). Strength training decreases inflammation and increases cognition and physical fitness in older women with cognitive impairment. Frontiers in Physiology, 8. https://doi.org/10.3389/fphys.2017.00377

Clark, B. C. and Manini, T. M. (2012). What is dynapenia? Nutrition, 28(5), 495-503. https://doi.org/10.1016/..nut.2011.12.002

Coelho-Júnior, H. J., de Oliveira Gonçalvez, I., Sampaio, R. A. C. et al. (2019). Periodized and nonperiodized resistance training programs on body composition and physical function of older women. Experimental Gerontology, 121, 10-18. https://doi.org/10.1016/j.exger.2019.03.001

Cohen, J. (2013). Statistical power analysis for the behavioral sciences. Academic press. https://doi.org/10.4324/9780203771587

Colado, J. C., Garcia-Masso, X., Pellicer, M., Alakhdar, Y., Benavent, J. and Cabeza-Ruiz, R. (2010). A comparison of elastic tubing and isotonic resistance exercises. International Journal of Sports Medicine, 31(11), 810-817. https://doi.org/10.1055/s-0030-1262808

Colado, J. C., Garcia-Masso, X., Triplett, N. T., Calatayud, J., Flandez, J., Behm, D. and Rogers, M. E. (2014). Construct and concurrent validation of a new resistance intensity scale for exercise with Thera-Band® elastic bands. Journal of Sports Science \& Medicine, 13(4), 758-766.

Colado, J. C., Pedrosa, F. M., Juesas, A., Gargallo, P., Carrasco, J. J., Flandez, J., Chupel, M. U., Teixeira, A. M. and Naclerio, F. (2018). Concurrent validation of the OMNI-Resistance Exercise Scale of perceived exertion with elastic bands in the elderly. Experimental Gerontology, 103, 11-16. https://doi.org/10.1016/i.exger.2017.12.009 
Colado, J. C. and Triplett, N. T. (2008). Effects of a short-term resistance program using elastic bands versus weight machines for sedentary middle-aged women. Journal of Strength and Conditioning Research, 22(5), 1441-1448. https://doi.org/10.1519/JSC.0b013e31817ae67a

da Rosa Orssatto, L. B., Cadore, E. L., Andersen, L. L. and Diefenthaeler, F. (2019). Why fast velocity resistance training should be prioritized for elderly people. Strength \& Conditioning Journal, 41(1), 105-114. https://doi.org/10.1519/SSC.0000000000000407

de Resende-Neto, A. G., Andrade, B. C. O., Cyrino, E. S., Behm, D. G., De-Santana, J. M. and Da SilvaGrigoletto, M. E. (2019). Effects of functional and traditional training in body composition and muscle strength components in older women: A randomized controlled trial. Archives of gerontology and geriatrics, 84, 103902. https://doi.org/10.1016/j.archger.2019.103902

Duncan, P. W., Weiner, D. K., Chandler, J. and Studenski, S. (1990). Functional reach: a new clinical measure of balance. Journal of gerontology, 45(6), M192-M197. https://doi.org/10.1093/geronj/45.6.M192

Dvir, Z. (2004). Isokinetics: muscle testing, interpretation, and clinical applications. Edinburgh; New York: Churchill Livingstone.

Eurostat (2020). Population structure and ageing. European Statistics. Data extracted in August 2020. Retrieved from: http://ec.europa.eu/eurostat/statisticsexplained/index.php/Population_structure_and_ageing\#The_share_of_elderly_people_continues_t o_increase

Evans, W. J., Paolisso, G., Abbatecola, A. M., Corsonello, A., Bustacchini, S., Strollo, F. and Lattanzio, F. (2010). Frailty and muscle metabolism dysregulation in the elderly. Biogerontology, 11(5), 527536. https://doi.org/10.1007/s10522-010-9297-0

Fritz, N. B., Juesas, A., Colado, J. C., Gargallo, P., Calatayud, J., Fernández-Garrido, J. and Rogers, M. E. (2018). Positive effects of a short-term intense elastic resistance training program on body composition and physical functioning in overweight older women. Biological Research for Nursing, 20(3), 321-334. https://doi.org/10.1177/1099800418757676

Fragala, M. S., Cadore, E. L., Dorgo, S., Izquierdo, M., Kraemer, W. J., Peterson, M. D. and Ryan, E. D. (2019). Resistance training for older adults: position statement from the national strength and conditioning association. Journal of Strength \& Conditioning Research, 33(8). https://doi.org/10.1519/JSC.0000000000003230

Gargallo, P., Colado, J. C., Juesas, A. et al. (2018). The effect of moderate-versus high-intensity resistance training on systemic redox state and DNA damage in healthy older women. Biological research for nursing, 20(2), 205-217. https://doi.org/10.1177/1099800417753877

Gray, M., Powers, M., Boyd, L. and Garver, K. (2018). Longitudinal comparison of low- and high-velocity resistance training in relation to body composition and functional fitness of older adults. Aging Clinical and Experimental Research, 30, 1465-1473. https://doi.org/10.1007/s40520-018-0929-6

Henwood, T. R, Riek S. and Taaffe D.R. (2008). Strength versus muscle power-specific resistance training in community-dwelling older adults. Journals of Gerontology Series A Biological Sciences and Medical Sciences, 63, 83-91. https://doi.org/10.1093/gerona/63.1.83

Holmes, J., Powell-Griner, E., Lethbridge-Cejku, M. and Heyman, K. (2009). Aging differently: Physical limitations among adults aged 50 years and over: United States, 2001-2007. NCHS data brief, (20), 1-8. https://doi.org/10.1037/e665252010-001

Huang, S.-W., Ku, J.-W., Lin, L.-F., Liao, C.-D., Chou, L.-C. and Liou, T.-H. (2017). Body composition influenced by progressive elastic band resistance exercise of sarcopenic obesity elderly women: a pilot randomized controlled trial. European Journal of Physical and Rehabilitation Medicine, 53(4), 556-563. 
Kramer, J. F. (1990). Reliability of knee extensor and flexor torques during continuous concentriceccentric cycles. Archives of Physical Medicine and Rehabilitation, 71(7), 460-464.

Leite, J. C., Forte, R., de Vito, G., Boreham, C. A. G., Gibney, M. J., Brennan, L. and Gibney, E. R. (2015). Comparison of the effect of multicomponent and resistance training programs on metabolic health parameters in the elderly. Archives of Gerontology and Geriatrics, 60(3), 412-417. https://doi.org/10.1016/j.archger.2015.02.005

Leyva A., Balachandran A. and Signorile J. F. (2016). Lower-body torque and power declines across six decades in three hundred fifty-seven men and women: A cross-sectional study with normative values. Journal of Strength and Conditioning Research 30, 141-158. https://doi.org/10.1519/JSC.0000000000001083

Liao, C.-D., Tsauo, J.-Y., Huang, S.-W., Ku, J.-W., Hsiao, D.-J. and Liou, T.-H. (2018). Effects of elastic band exercise on lean mass and physical capacity in older women with sarcopenic obesity: a randomized controlled trial. Scientific Reports, 8(1), 2317. https://doi.org/10.1038/s41598-018$\underline{20677-7}$

Lohman, M., Tallroth, K., Kettunen, J. A. and Marttinen, M. T. (2009). Reproducibility of dual-energy xray absorptiometry total and regional body composition measurements using different scanning positions and definitions of regions. Metabolism: Clinical and Experimental, 58(11), 1663-1668. https://doi.org/10.1016/j.metabol.2009.05.023

Lord, J. P., Aitkens, S. G., McCrory, M. A. and Bernauer, E. M. (1992). Isometric and isokinetic measurement of hamstring and quadriceps strength. Archives of Physical Medicine and Rehabilitation, 73(4), 324-330. https://doi.org/10.1016/0003-9993(92)90004-G

Manini, T. M., Visser, M., Won-Park, S., Patel, K. V., Strotmeyer, E. S., Chen, H., ... Harris, T. B. (2007). Knee extension strength cutpoints for maintaining mobility. Journal of the American Geriatrics Society, 55(3), 451-457. https://doi.org/10.1111/j.1532-5415.2007.01087.x

Martins, W. R., de Oliveira, R. J., Carvalho, R. S., de Oliveira Damasceno, V., da Silva, V. Z. M. and Silva, M. S. (2013). Elastic resistance training to increase muscle strength in elderly: a systematic review with meta-analysis. Archives of Gerontology and Geriatrics, 57(1), 8-15. https://doi.org/10.1016/j.archger.2013.03.002

Moreira, N. B., Rodacki, A. L. F., Pereira, G. and Bento, P. C. B. (2018). Does functional capacity, fall risk awareness and physical activity level predict falls in older adults in different age groups? Archives of Gerontology and Geriatrics, 77, 57-63. https://doi.org/10.1016/j.archger.2018.04.002

Oesen, S., Halper, B., Hofmann, M., Jandrasits, W., Franzke, B., Strasser, E.-M., ... Wessner, B. (2015). Effects of elastic band resistance training and nutritional supplementation on physical performance of institutionalised elderly- A randomized controlled trial. Experimental Gerontology, 72, 99-108. https://doi.org/10.1016/j.exger.2015.08.013

Orssatto, L. B., Cadore, E. L., Andersen, L. L. and Diefenthaeler, F. (2019). Why fast velocity resistance training should be prioritized for elderly people. Strength and Conditioning Journal, 1-10. https://doi.org/10.1519/SSC.0000000000000407

Prior, B. M., Cureton, K. J., Modlesky, C. M., Evans, E. M., Sloniger, M. A., Saunders, M. and Lewis, R. (1997). In vivo validation of whole-body composition estimates from dual-energy X-ray absorptiometry. Journal of Applied Physiology, 83(2), 623-630. https://doi.org/10.1152/jappl.1997.83.2.623

Radaelli, R., Brusco, C. M., Lopez, P., Rech A., Machado C. L., Grazioli R., Muller, D. C., Cadore, E.L. and Pinto R. S. (2018). Higher muscle power training volume is not determinant for the magnitude of neuromuscular improvements in elderly women. Experimental Gerontology, 110, 15-22. https://doi.org/10.1016/j.exger.2018.04.015 
Reid, K. F, Callahan, D. M., Carabello, R.J., et al. (2008) Lower extremity power training in elderly subjects with mobility limitations: a randomized controlled trial. Aging Clinical and Experimental Research, 20, 337-343. https://doi.org/10.1007/BF03324865

Reid, K. F. and Fielding R. (2012). Skeletal muscle power: A critical determinant of physical functioning in older adults. Exercise and Sport Sciences Reviews, 40, 4-12. https://doi.org/10.1097/JES.0b013e31823b5f13

Reid, K.F., Martin, K.I., Doros, G., Clark, D. J., Hau, C., Patten, C., Phillips, E. M., Frontera W.R. and Fielding R. A. (2015). Comparative effects of light or heavy resistance power training for improving lower extremity power and physical performance in mobility-limited older adults. Journals of Gerontology Series A Biological Sciences and Medical Sciences, 70, 374-380. https://doi.org/10.1093/gerona/glu156

Rikli, R. E., \& Jones, C. J. (2013). Senior fitness test manual. Human kinetics.

Sander M., Oxlund B., Jespersen A., Krasnik A. Mortensen E. L., Westendorp R. G. J. and Rasmussen, L.J. (2015). The challenges of human population ageing. Age and Ageing, 44, 185-187. https://doi.org/10.1093/ageing/afu189

Snow, C. J. and Blacklin, K. (1992). Reliability of knee flexor peak torque measurements from a standardized test protocol on a Kin/Com dynamometer. Archives of Physical Medicine and Rehabilitation, 73(1), 15-21.

Straight, C. R., Lindheimer, J. B., Brady, A. O., Dishman, R. K. and Evans, E. M. (2015). Effects of resistance training on lower-extremity muscle power in middle aged and older adults: a systematic review and meta-analysis of randomized controlled trials. Sports Medicine, 46, 353-364. https://doi.org/10.1007/s40279-015-0418-4

Tschopp, M., Sattelmayer, M. K. and Hilfiker, R. (2011). Is power training or conventional resistance training better for function in elderly persons? A meta-analysis. Age and Ageing, 40, 549-556. https://doi.org/10.1093/ageing/afr005

von Haehling S., Morley J. E. and Anker S. D. (2010). An overview of sarcopenia: Facts and numbers on prevalence and clinical impact. Journal of Cachexia Sarcopenia, and Muscle 1: 129-133, 2010. https://doi.org/10.1007/s13539-010-0014-2

Wannamethee, S. G. and Atkins, J. L. (2015). Muscle loss and obesity: the health implications of sarcopenia and sarcopenic obesity. Proceedings of the Nutrition Society, 74(4), 405-412. https://doi.org/10.1017/S002966511500169X

\section{() $\odot \Theta \Theta$}

This work is licensed under a Attribution-NonCommercial-NoDerivatives 4.0 International (CC BY-NC-ND 4.0). 